$$
\begin{gathered}
\text { UCRL-JC-118376 } \\
\text { PREPRINT } \\
\text { CONF-9409 } 202--4
\end{gathered}
$$

\title{
Micromachined Fabry-Perot Interferometric Pressure Sensor for Automotive Combustion Engine
}

\author{
S. B. Lee \\ C. M. Yu \\ D. R. Ciarlo \\ S. K. Sheem
}

RECEIVED

APR 051996

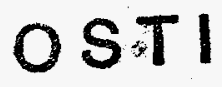

This paper was prepared for submittal to the Sensors Expo

Cleveland, Ohio

September 20-22, 1994

September 1994

This is a preprint of a paper intended for publication in a journal orproceedings. Since changes may be made before publication, this preprint is made available with the understanding that it will not be cited or reproduced without the permission of the author.
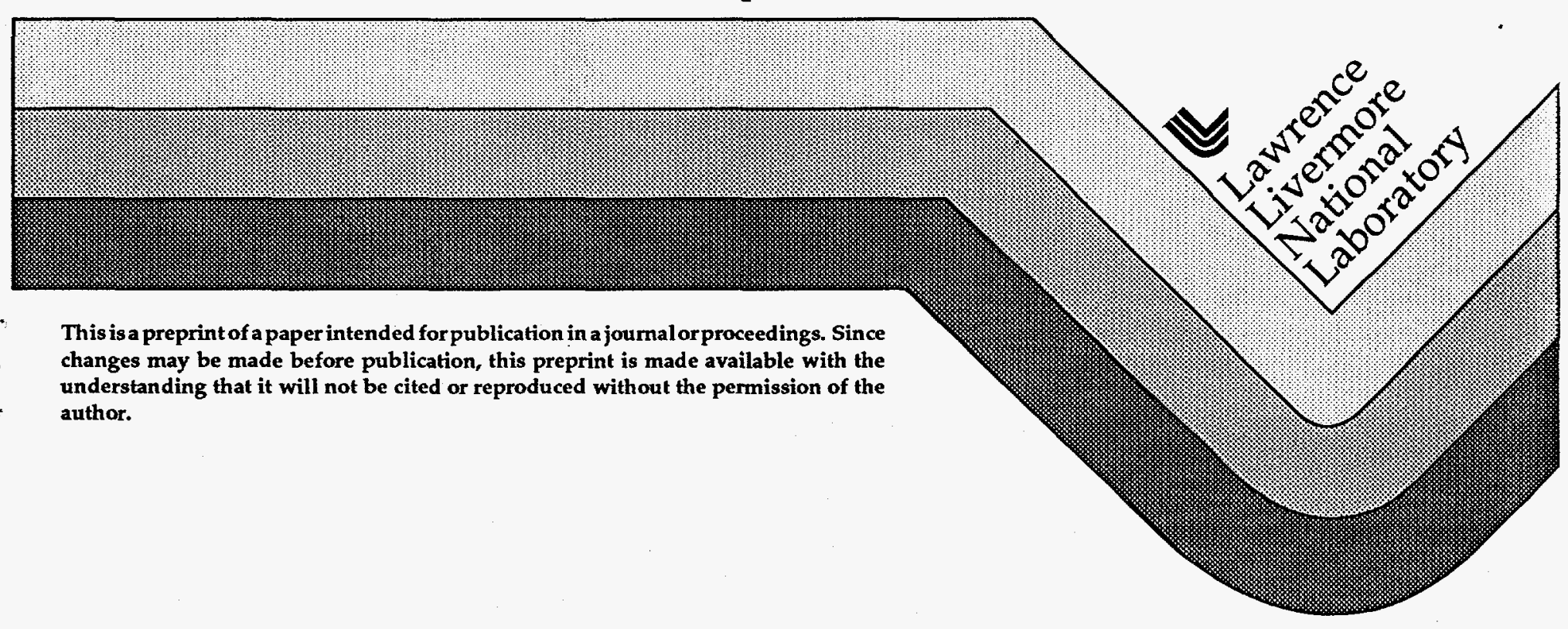


\section{DISCLAIMER}

This document was prepared as an account of work sponsored by an agency of the United States Government. Neither the United States Government nor the University of California nor any of their employees, makes any warranty, express or implied, or assumes any legal liability or responsibility for the accuracy, completeness, or usefulness of any information, apparatus, product, or process disclosed, or represents that its use would not infringe privately owned rights. Reference herein to any specific commercial product, process, or service by trade name, trademark, manufacturer, or otherwise, does not necessarily constitute or imply its endorsement, recommendation, or favoring by the United States Government or the University of California. The views and opinions of authors expressed herein do not necessarily state or reflect those of the United States Government or the University of California, and shall not be used for advertising or product endorsement purposes. 


\section{DISClaImer}

Portions of this document may be illegible in electronic image products. Images are produced from the best available original document. 


\title{
Micromachined Fabry-Perot Interferometric Pressure Sensor for Automotive Combustion Engine
}

\author{
S.B. Lee, C.M. Yu, D.R. Ciarlo, and S.K. Sheem \\ Lawrence Livermore National Laboratory \\ Livermore, CA 94551
}

\begin{abstract}
In this paper, we report a dynamic cylinder pressure sensor for automotive combustion engine. The pressure is sensed by measuring the pressure-induced deflection of a membrane via a Fabry-Perot optical interfrometric effect. The sensor is micromachined on a silicon wafer to minimize the cost and the size and to enhance the device quality in high-volume production mode. As a preliminary test, we measured the pressure of an air compressor using the micromachined miniature sensor.
\end{abstract}

\section{Introduction}

The Fabry-Perot interferometer has been widely used for highresolution spectroscopy $[1,2]$, highprecision measurement [3], and other physical sensing [4]. Recently, there has been substantial interest in micromachined miniature sensors for measuring pressure and temperature [57].

In automotive engines, the measurement of dynamic cylinder pressure can be used for improving engine efficiency and reducing the pollutants by inputing the data instantly to the on-board engine control system. The automotive combustion engine presents a very harsh environment with the temperature reaching $400{ }^{\circ} \mathrm{C}$ near the spark plug and the pressure of up to $8 \mathrm{MPa}$ (1160 psi). In addition, the sensor should be very inexpensive and small.

In this paper, we present design and fabrication of the fiber-optic pressure sensor which is suitable for the automotive application, and test results from this pressure sensor. Our test results indicate that a high dynamic range and a good linear response can be achieved.

\section{Theoretical background}

Fabry-Perot cavity is formed by two light-reflecting surfaces. The amount of light passing through the cavity depends on the separation between the two reflecting surfaces. Accordingly, if one of the surface is made of a membrane that deflects by pressure, the light output changes according to the amount of the mambrane deflection. More detailed description of this working mechanism is given below.

First, the phase of the wavelength $\lambda$ in the cavity as a function of the separation $s$ of the two surfaces can be written as $\phi(s)=n s \cos \theta(4 \pi / \lambda)+\varepsilon$, where $\phi=$ phase, $n=$ index of refraction, $\theta=$ angle of incidence, $\varepsilon=$ phase change occurring on reflection [8]. For a light source whose spectral lineshape and its intensity profile are given as $f(\lambda), I_{o}(r)$, respectively, the fringe pattern can be written as 


$$
\begin{aligned}
& I_{T}(s)=I_{o} \exp \left[-2 r^{2} / r_{o}\right](1-\beta) \\
& \times G \int_{-\infty}^{\infty} L(\phi) f(\lambda)\left[1+F \sin ^{2}(\phi / 2)\right]^{-1} d \lambda,
\end{aligned}
$$

where $\quad G=\left|T_{1}\right|^{2}\left|T_{2}\right|^{2} /\left(1-\alpha R_{1} R_{2}\right)^{2}$, $F=4 \alpha R_{1} R_{2} /\left(1-\alpha R_{1} R_{2}\right)^{2} . T$ and $R$ are the transmission and reflection coefficients, respectively. The $\alpha$ in $F$ and $G$ represents attenuation per pass [9]. $r$ is the radial distance from the center of the circular beam; i.e., at $r_{j}=r_{0 j}$, the intensity decreases to $1 / e^{2}$. Eq. (1) assumes the laser light source in which the spectral line width would typically be less than $1 \%$ of the peak wavelength. Also we assumed the spatial intensity distribution of Gaussian profile, which results in 'Newton's rings' interference pattern spatially. $\beta$ represents the reflection loss due to the change in shape of the sensing membrane, the second surface. This coefficient $\beta$ could be negligible since the size of a sensing membrane is normally comparable to or larger than that of a beam spot so that the membrane is assumed to be planar. Even at the maximum amount of deflection at membrane center before fracture [10], it would not be a significant factor. The term $L$ expresses the loss due to the broadening of initial intensity profile, and is given by

$$
\cong \frac{\int_{-b}^{L(\phi(s) ; \ell)} \exp \left[-\left\{r /\left(\Delta_{r}+\ell \tan \varphi\right)\right\}^{2}\right] r d r}{\int_{-a}^{a} \exp \left[-\left\{r / \Delta_{r}\right\}^{2}\right] r d r},
$$

where $\varphi$ is either the apex half-angle of divergent circular beam or the halfangle given by the numerical aperture of a fiber, $l$ is the total length the beam traveled in the cavity and $\Delta_{r}$ is the halfwidth in $r$. For an optical fiber to send and receive light, $a=b$ and $l=2 s$ where the beam divergent angle is limited by the fiber numerical aperture.

Eq. (1) can readily be integrated at each given separation to give the overall fringe pattern. We have made several calculations of fringe pattern with Gaussian spectral line shape $f(\lambda) \sim$ $\exp \left[-\left(\lambda-\lambda_{0} / \Delta\right)^{2}\right]$, with a half-width $\Delta$ and peak wavelength $\lambda_{0}$. The result from the calculation with $\lambda_{0}=1310 \mathrm{~nm}$ is shown in Fig. 1. A Lorenzian spectral line distribution was also tried, and the results were very similar to a Gaussian case.

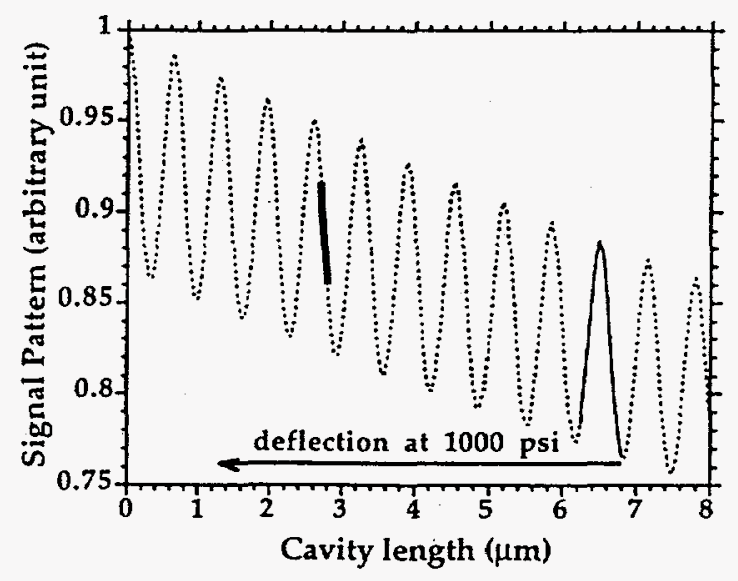

Fig. 1. The theoretical signal pattern from Eq. (1) with $\lambda_{0}=1310 \mathrm{~nm}, \Delta=5 \mathrm{~nm}, \mathrm{R}_{1}=0.04, \mathrm{R}_{2}=$ 0.9 with $1 \%$ loss per pass. The laser light is being transmitted through the optical fiber whose dimension is $100 / 140 \mu \mathrm{m}$ with the numerical aperture 0.2. The dark strip shows, for example, a region where the signal should be biased for the pressure $15-1200$ psi.

The integration limits of up to $30 \Delta$ with double precision have been checked yielding the accuracy of within $0.1 \%$ to that of $10 \Delta$. The optimum value of the 
integration step in $\lambda$ was obtained by reducing the size of the step by half until the results were stable and changed by less than $0.1 \%$. Typically, the integration step of 0.1 angstrom is used. It should be noted that a sensitivity calculation may also be carried out numerically by differentiating Eq. (1) with respect to the phase [9].

\section{Sensor design and fabrication}

We picked the cavity length $(6.8$ $\mu \mathrm{m})$ and the amount of the membrane deflection $(0.65 \mu \mathrm{m})$ such that the experimental dynamic range $(15-120$ psi) of the pressure given by the air compressor would produce one full fringe $\left(\lambda_{\mathrm{o}} / 2\right)$ including the fabrication tolerance of $\sim 5 \%$. In Fig. 1, the expected resulting signal pattern is shown as the solid line for the dynamic pressure testing. In case of the static testing with pressure from $15(1 \mathrm{~atm})$ to $1000 \mathrm{psi}$, this model predicts that we would observe 8.5 fringes at the deflection of $5.5 \mu \mathrm{m}$. This theoretical modeling also facilitates the bias point calibration.

In order to design the sensor with the square membrane, we use the equation [11], $d=0.0138 \mathrm{~Pa}^{4} / E t^{3}$, where $d$ is the maximum deflection at the center of the membrane, $P$ the pressure, $a$ the width, $E$ the Young's modulus, and $t$ the thickness of the membrane. We fabricated the sensor on a $200 \mu \mathrm{m}$ thickSilicon wafer using the micromachining techniques. The overall view of the sensor is drawn in Fig. 2. The sensor is attached to the end of the Corning Pyrex tube with $1 \mathrm{~mm}$ inside diameter (ID). The depth of etching in one side is 6.8 $\mu m$ which is the separation of the two surfaces. The reason we choose this gap is that LED light source can be used and tested for economical reason in the future. Since LED has much larger spectral bandwidth, the interference pattern quickly disappears as the cavity length increases. Its coherence length is much shorter than that of laser.

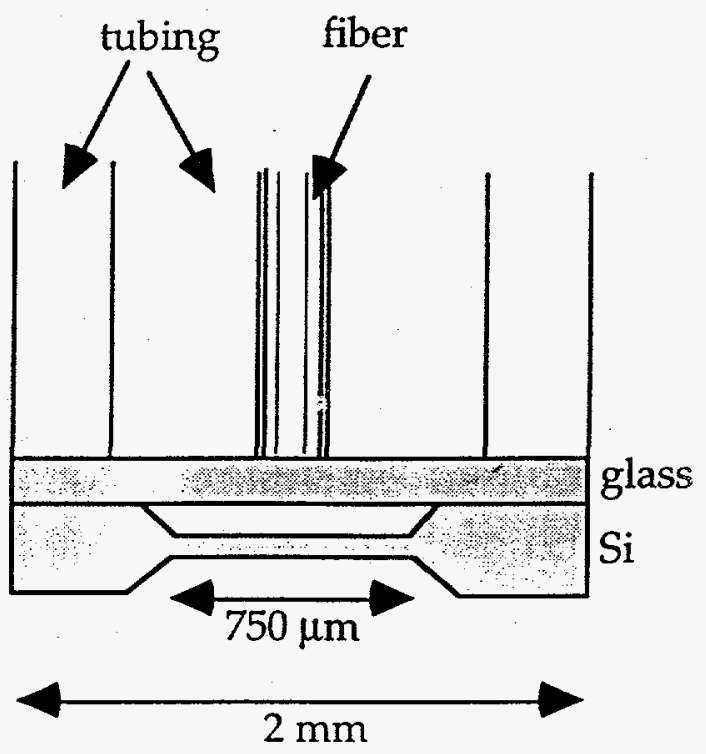

Fig. 2. Schematic of sensor structure. The light is sent and received through the $100 \mu \mathrm{m}$ core fiber. The cavity length is about $7 \mu \mathrm{m}$ and the thickness of the membrane is $8 \mu \mathrm{m}$. The drawing is not in scale.

The miniaturized mechanical membrane structures employed here were fabricated on silicon wafers using anisotropic etching technique in potassium hydroxide. After the precise alignment of the masking patterns on both sides of the silicon wafer, a photolithographically-formed window was etched to a depth of $178 \mu \mathrm{m}$ on only one side first. The both sides were then etched to a depth of $7 \mu \mathrm{m}$. which yielded the required cavity depth and the membrane thickness of $8 \mu \mathrm{m}$. Upper side of the membrane in a (100) crystal plane where the reflection should occur was polished to optical quality and its depth variation was checked with an 
interferometer. A portion of the 2-inch diameter silicon wafer containing 144 micromachined sensor chips is shown in Fig. 3 as well as a photograph of the assembled pressure sensor.

(a)

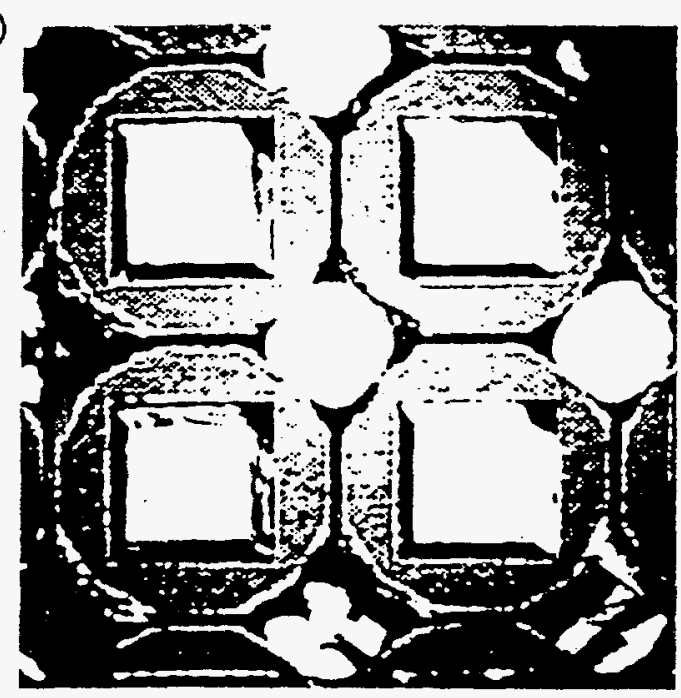

(b)

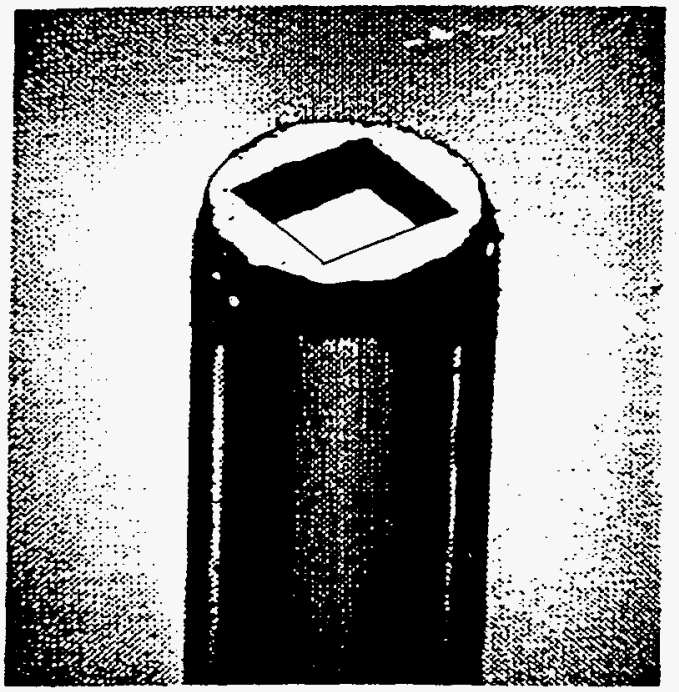

Fig. 3 (a) Photograph of a portion of the silicon wafer in which 144 sensor-chips are micromachined. (b) Photograph of the pressure sensor where the window is larger than the membrane size because of the,etching angle.

The trapezoidal structure defining the (I11) crystal plane is apparent in both photographs. The actual window opening to create the desired membrane size was accurately determined by considering the etching angle of $54.7^{\circ}$ to a $<100>$ direction.

The width of the pressuresensing membrane is $750 \mu \mathrm{m}$, and the thickness is $8 \mu \mathrm{m}$. The first surface is formed by the $130 \mu \mathrm{m}$ thick glass flat which is cemented to the silicon surface. The fiber with $100 / 140 \mu \mathrm{m}$ is centered by the secondary glass tubing whose ID is $150 \mu \mathrm{m}$. The interference pattern due to two surfaces formed by glass microslide itself is negligible. In application to an actual automotive engine, the Corning 7740 Pyrex slide will be anodically bonded. A vent hole will be provided to the micromachined cavity to make sure that the membrane deflection is not impeded at a higher pressure due to the resistance from the compressed air that is otherwise trapped in the cavity.

\section{Experimental results}

The pressure test set-up we used is depicted in Fig. 4. We tested the sensor under the dynamic pressure from air compressor whose combustion cycle is $34 . \mathrm{msec}$ and under the static pressure from Nitrogen gas.

First, the result from the dynamic pressure testing with the air compressor is illustrated in Fig. 5. The response of our sensor (bottom) matched well with that of a commercial sensor (top). Although the sensors were not mounted directly to the cylinder of the air compressor, we ovserved that the temperature of the pressure chamber reached about $70{ }^{\circ} \mathrm{C}$, at which point the commercial piezo-sensor stopped working properly. 


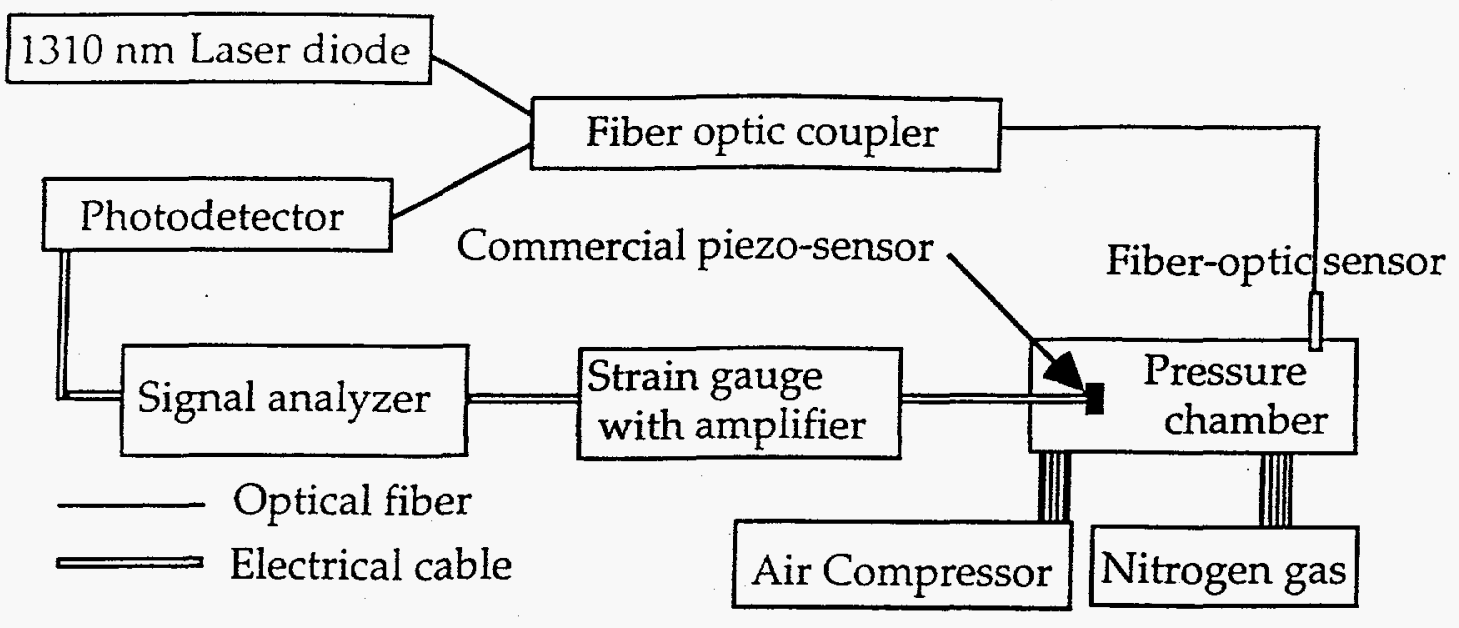

Fig. 4. Block diagram of the experimental configuration. Laser diode with $1310 \mathrm{~nm}$-wavelength is used with 100/140 multimode fibers and a coupler. The two-channel oscilloscope facilitates the signal analysis from the two different sensors.

However, our sensor continued to yield the same performance at the elavated temperature. Since the cavity length is shorter than a few micron, and the sensor is all assembled made of silicon and glass, its performance variation due to thermal expansion would be minimal. Also, the temperature dependence in Young's modulus is negligible and thus the resulting waveform would be stable over the expected automotive engine temperature range.

Fig. 6 depicts the result from the static pressure testing. It clearly exhibits that there are about 8.5 fringes during the time of which the pressure is increased from 15 (1 atm) to 1000 psi. This was predicted in our design. It should be noted that we recovered the identical time-reversed signal pattern when the pressure was released from 1000 to 15 psi.

In the future design we are planning to increase the memberane thickness so that the output is confined within the linear region, as represented by the dark strip in Fig. 1, for the dynamic pressures up to 1200 psi, which is the expected maximum value for an automotive engine.

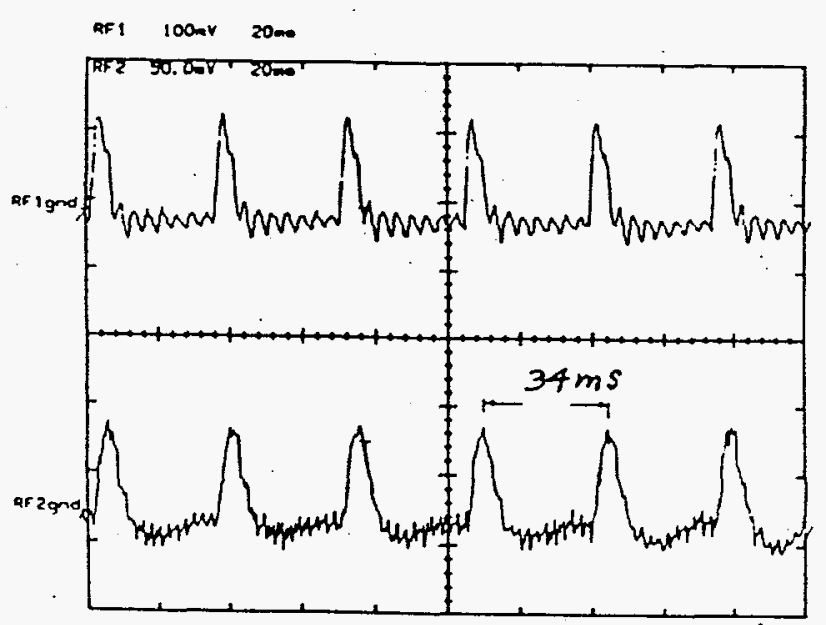

Fig. 5. Response of the fiber-optic sensor at the bottom is compared with that from the commercial sensor at the top for the drnamic pressures of $15-120$ psi. 


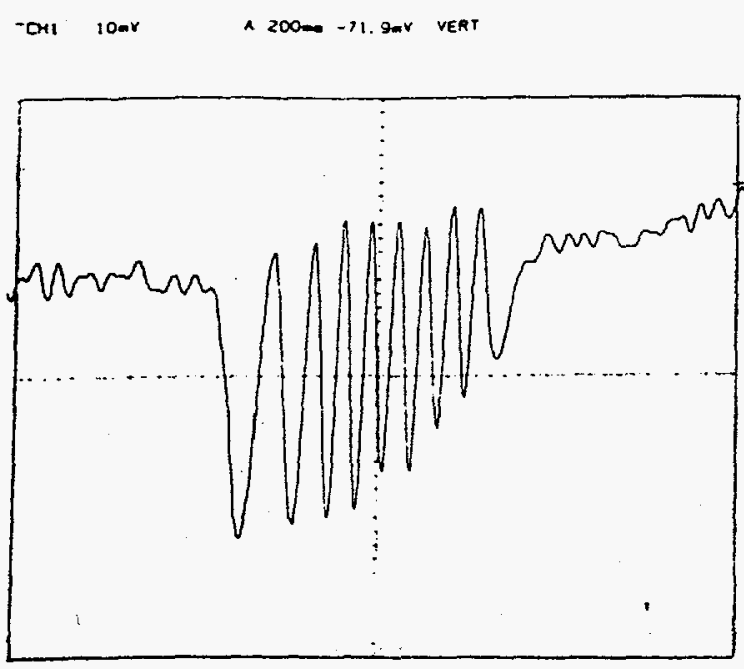

Fig. 6. Response of the fiber-optic sensor is shown for static pressures of $15-1000$ psi. It clearly exhibits 8.5 fringes. No signal amplifier is used for this output.

\section{Conclusion}

It has been shown that our newly designed sensor based on the theoretical model largely met the expectations well. On the other hand, it is still far from the actual commercial use of this sensor since there are many elements to be studied further. In the future, we will incorporate LED source so that this sensor is more economically viable. A more detailed study will be followed elsewhere.

The authors acknowledge AC Rochester, a division of General Motors for their support. This work was performed under auspices of the U.S. Department of Energy by the Lawrence Livermore National Laboratory under contract No. W-7405-ENG-48.

\section{References}

[1] B. Cagnac, High resolution spectroscopy zith multiple-beam laser techniques, Phil. Trans. R. Soc. A307, 633-44 (1982).
[2] K. Shimoda, Limits of sensitivity of laser spectrometers, Appl. Phys. 1, 77-86 (1973).

[3] J.M. Vaughan, The Fabry-Perot Interferometer(AdamHilger, Philadelphia, 1989).

[4] T. Yoshino, K. Jurosawa, K. Itoh, T. Ose, Fiber-optic Fabry-Perot interferometer and its sensor applications, IEEE Trans. Micro. Theory Tech. MTT-30, 1612-1621 (1982).

[5] G. Beheim, K. Fritsch, R.N. Poorman, Fiber-linked interferometric pressure sensor, Rev. Sci. Instrum. 58 (9), 1655-1659 (1987).

[6] R.A. Wolthuis, G.L. Mitchell, E. Saaski, J.C. Hartl, M.A. Afromowitz, Development of medical pressure and temperature sensors employing optical spectrum modulation, IEEE Trans. Biomed. Engineering, 38, 974-981 (1991).

[7] X.Tu, J.N. Zemel, Verticalmembrane optical-fiber pressure sensor, Sensors and Actuators A, 39, 49-54, 1993.

[8] H. Kogelnik, Theory of dielectric waveguides in Integrated Optics, $\mathrm{T}$. Tamir (Editor) (Springer-Verlag, N.Y. 1975). pp13-81.

[9] S.J. Petuchowski, T.G. Giallorenzi, S.K. Sheem, $A$ sensitive fiber-optic Fabry-Perot interferometer, IEEE J. Quan. Elec. QE-17, 2168-2170, 1981.

[10] L.E. Trimble, G.K. Celler, J. Frackoviak, G.R. Weber, Membrane fragility: fact of illusion?, J. Vac. Sci. Tech. B. 10 (6), 32003203, 1992.

[11] R.J. Roark, Formulas for stress and strain (4th edition), (McGrawHill, N.Y. 1965); see also E.A. Avallone, T. Baumeister III, Mark's standard handbook for mechanical engineers (9th edition), (McGrawHill, N.Y. 1986).

[12] P.M. Morse, Vibration and sound (AIP, N.Y. 1981). 